University of Nebraska - Lincoln

DigitalCommons@University of Nebraska - Lincoln

Fall 1982

\title{
Father Absence and Reproductive Strategy: An Evolutionary Perspective
}

\author{
Patricia Draper \\ University of Nebraska - Lincoln, pdraper1@unl.edu \\ Henry Harpending \\ University of Utah, henry.harpending@anthro.utah.edu
}

Follow this and additional works at: https://digitalcommons.unl.edu/anthropologyfacpub

Part of the Anthropology Commons

Draper, Patricia and Harpending, Henry, "Father Absence and Reproductive Strategy: An Evolutionary Perspective" (1982). Anthropology Faculty Publications. 38.

https://digitalcommons.unl.edu/anthropologyfacpub/38

This Article is brought to you for free and open access by the Anthropology, Department of at DigitalCommons@University of Nebraska - Lincoln. It has been accepted for inclusion in Anthropology Faculty Publications by an authorized administrator of DigitalCommons@University of Nebraska - Lincoln. 


\title{
JOURNAL OF ANTHROPOLOGICAL RESEARCH
}

$\begin{array}{llllll}\text { VOLUME } 38 & \bullet & \text { NUMBER } 3 & \bullet & \text { FALL } & \bullet\end{array}$

\section{FATHER ABSENCE AND REPRODUCTIVE STRATEGY : AN EVOLUTIONARY PERSPECTIVE ${ }^{1}$}

\author{
Patricia Draper \\ Henry Harpending \\ Department of Anthropology, University of New Mexico, Albuquerque, NM 87131
}

\begin{abstract}
Explanations offered by social scientists for the effects of father absence on children are reviewed; certain aspects of these interpretations are found wanting. Another explanation using theory from evolutionary biology is suggested: children show evolved, sensitive-period learning in early childhood which is linked to mother's pair-bond status or to mother's attitude toward males. As a result of children's perceptions a developmental track is established, which influences expression of reproductive strategy in adulthood. Male children born into matrifocal households exhibit at adolescence a complex of aggression, competition, low male parental investment, and derogation of females and feminity, while females show early expression of sexual interest and assumption of sexual activity, negative attitudes toward males, and poor ability to establish long-term relationships with one male. Male children reared in father-present or nuclear households show less interest in competitive dominance with other males and more interest in manipulation of nonhuman aspects of the environment, while females show delayed sexual interest and activity and a mating strategy directed at locating a male who will invest in her and her offspring.
\end{abstract}

THE DOMESTIC CIRCUMSTANCES in which children are reared is the subject of widespread attention. It is no accident that children should receive the full glare of analytic scrutiny in our social sciences, since an understanding of how a novice is incorporated into an ongoing system reveals much about the nature of that system. Furthermore, novices can be marked and traced through their training as social actors. Paying close attention to a child's career as learner and joiner can reveal much of what is hidden to an observer of adult social behavior-guided as it is by habits formed long ago and by current perceptions too complex and too intimate to be asked about.

The purposes of this paper are to examine two polar rearing circumstances which children experience and to offer a somewhat novel explanation for the outcomes of the two types of rearing. Father-present rearing is one in which mother and father jointly and simultaneously provision and educate (in the broader sense of the term) the young. Father-absent rearing is one in which the mother, in the absence of regular assistance from the father, carries the major responsibility for provisioning and educating them. Father absence has been a prominent topic in the fields of education, sociology, and psychology, although in the last decade or so literature on the topic has tapered off. Recent reviews of father absence are found in Lynn (1974), 
Lamb (1976), Biller (1976), and Hamilton (1977); discussions of father absence across cultures found are in Whiting and Whiting (1975), Munroe, Munroe, and J. Whiting (1980).

We consider that research on father absence has been hampered by the fact that most researchers are products of Western culture and upper socioeconomic class, where the ideal type is the father-present household. There is in the literature on the subject a frank bias to the effect that father-absent households are lacking a critical element and that remedial or enrichment measures must be taken to protect against the ill effects of this weakened structure. It is possible, indeed likely, that children can benefit in some respects from the two-parent model approved in our own society as well as in some others which lack advanced technology (Biller 1971; Blanchard and Biller 1971; Hamilton 1977; Nash 1965, 1976). It should not be assumed, however, that father-absent upbringing everywhere brings with it deleterious effects.

Our interest in this paper is to consider the two household types as differing but equally sound structural types within which mating and provisioning of the young can occur. We agree with some of the findings regarding social and behavioral outcomes for children reared in the two contexts, but we disagree with the predominantly negative interpretation given to the consequences of father-absent upbringing. We suggest, instead, that there is a larger, more inclusive context within which adaptive value can be seen in both father absence and father presence.

Before proceeding further it should be mentioned that father-absent households are found in two distinct normative environments. In the first it is more common to find father-absent households concentrated among the lower socioeconomic groups in technologically advanced and/or stratified societies. Members of these economically depressed groups are aware that the approved, legal form of union is one sanctified by church and state. Children who are products of this type of fatherabsent rearing suffer not only a more precarious existence because of their mother's economic status, but will also recognize that in certain sectors their household is considered deviant and inferior.

The second sort of father absence is found in many societies of the world where father-absent upbringing is the usual or normative arrangement. Women in these societies have husbands and their children recognize particular men as their fathers; however, prevailing customs regarding the division of labor and relations between the sexes are such that men and women, with their young children, have limited personal and social contact, even though the marriages themselves are durable and economically sound. Many pre-state, tribal-level societies are of this type.

Father absence, then, can be found in two contexts, contranormative and normative. Anthropologists were among the first to. recognize the importance of distinguishing the former from the latter and to determine whether the behavioral consequences for boys were different in the two cases. It is interesting that, in terms of certain behaviors observable in boys at adolescence and later ages, the consequences are the same, and a rich creative psychological literature has arisen to explain these effects. However, theories which deal with this phenomenon are inconvenienced by at least three problems. The first is that the effects of father absence are not the same for girls and boys. The second is that many of the measures require 
the subject to respond to paper-and-pencil tests designed to measure attitude, preference, and emotional response to sex-role concepts (as opposed to abilities). The scores attained by subjects who take such tests do not reliably correspond to objectively measurable or observable behavior. For example, father-absent boys may be either unusually aggressive for their age or unusually unaggressive and inhibited (as determined by test scores). The third problem with the psychological literature is the lack of longitudinal information on father-absent children. Not only do these subjects show mixed results on various paper-and-pencil tests, but because the usual research designs do not dictate repeated assessment of the same subjects at different developmental stages, researchers are uncertain about the stability of findings revealed through tests of attitude, cognitive style, and sex-role orientation.

The argument put forward in this paper is atypical in several ways. It focuses on only a subset of the variables thought to be associated with father absence-those which are primarily observable at adolescence, not during childhood. The variables of interest to this argument are related to sexual interest and mating strategy as that term is used by evolutionary biologists. In addition, our argument concerns itself strictly with behavioral variables and not with variables of a more abstract, inferential nature.

We propose that the diversity of outcomes of father absence makes a great deal of sense when it is considered in the framework of sensitive-period learning of reproductive strategies. We will be concerned with a set of widely replicable findings about growing up in a household without a resident father, which have to do with sexual behavior, defined broadly as behaviors faciliting mating and parenting. Many of these do not appear until adolescence, although some are foreshadowed in prepubertal children.

We are, therefore, seeking to link an admittedly complex set of conditions which we call "father absence," occurring in early childhood (roughly birth to five years of age), with outcomes which are not fully expressed until later in the child's life. In doing this we believe we can explain in a broad paradigm much interesting material which has accumulated regarding the sequelae of father absence for children. A brief account of some of the findings about father-absent children follows.

\section{CHARACTE RISTICS OF FATHER-ABSENT CHILDREN}

In comparison with control boys reared with fathers present during early childhood, father-absent adolescents are more likely to show many but not necessarily all of the following characteristics in a variety of societies: rejection of authority, particularly when it is imposed by adult females; exaggerated masculinity (often regarded by psychologists as "overcompensation" for insecure masculine sex-role identification); rejection and denigration of feminity; greater interpersonal aggressiveness; increased risk of arrest and incarceration; and a relatively exploitative attitude toward females, with sexual contact appearing important as conquest and as a means of validating masculinity (Rohrer and Edmonson 1960; Miller 1958; LeVine and LeVine 1966; Anderson 1968; Cohen 1955; Glaser 1965; Wylie and Delgado 1959; Nye 1957; Lynn and Sawrey 1959; Kelly and Baer 1969; Biller 1970, 1971; Biller and Bahm 1971). 
A further consistent finding is that father-absent boys show increased verbal ability and reduced spatial or quantitative ability on standardized tests of cognitive performance. Studies of cognitive abilities in males form the great bulk of the father-absence literature, since the phenomenon has important consequences for educational inequality among American social classes and ethinic groups (Moynihan 1965; Pettigrew 1964). The effect, however, is not limited to poor people. A study of freshmen at Harvard University whose fathers had either been at home or in the armed forces during World War II showed the following pattern of SAT scores (Table 1 ; Carlsmith 1964).

TABLE 1

SAT Scores of Harvard Freshmen

\begin{tabular}{lcc}
\hline & Father absent & Father present \\
Math & 668 & 716 \\
Verbal & 701 & 653 \\
\hline
\end{tabular}

Data like these are usually interpreted as "feminization" of father-absent boys, or rather, feminization of their cognitive style. When it occurs, increased aggressiveness and hypermasculine posturing is interpreted as "compensation" for this "feminization." We do not necessarily disagree with these interpretations; however, if we understood how these mechanisms evolved we might propose a more accurate gloss. Why should evolution have designed human males, but not females, to develop greater verbal ability and less spatial-quantitative ability when raised without a father in the household during early childhood?

Females, regardless of father absence or presence, show a consistent pattern on such tests: verbal ability superior to quantitative ability. There have been fewer studies and replications of the effects of father absence on the development of females. Since there are few reliable psychological or social effects in prepubertal females, educators have been more interested in elucidating the mechanisms leading to the spatial and quantitative deficits in males. Since girls are reared by adult females, they purportedly experience no discontinuity in sex role identification between the parent who provided the model for emulation and the expectations of society. However, at adolescence some father-absent girls differ from controls in the domain of what we are calling sexual behavior. Variables which have been studied include attitudes toward males and masculinity, interest in sexuality, timing of appearance of sexual interest, and interest in developing a stable relationship with one male. In general, father-absent girls show precocious sexual interest, derogation of masculinity and males, and poor ability to maintain sexual and emotional adjustment with one male (Hetherington 1972; Bloss 1969; Friedman 1969; Winch 1949, 1950; Leonard 1966; Nelson and Vangen 1971; Heckel 1963; Rainwater 1971; Hamilton 1977; Barglow et al., 1968).

There is a strong effect due to time of separation from the father. Most studies which have controlled for the age of the child or which have reported the age of the child show that father absence in the very early childhood years is the best predictor of strong effects on the child's behavior at later ages. The ages from one to five years are apparently the most critical for the child. Psychologists have recognized that 
there is a sensitive period for receptivity to fathering. Since Freud, psychoanalytically and developmentally oriented psychologists have worked with conceptual schemes involving periods of developmental readiness in building their models of learning and behavior. Our theory is different from, but not incompatiable with, the psychological theories. The approaches contrast in that psychological theories specify proximate causes, while evolutionary theory specifies ultimate causes; it specifies why the phenomena recognized by psychologists and anthropologists would have evolved in the first place, it suggests where one should seek specific mechanisms to explain the empirical findings, and it leads to further testable hypotheses. What selective advantage would have been conferred upon individuals who, during an early sensitive period, were able to learn (in our rather specialized usage) behaviors which could emerge at adolescence to facilitate one style or another of mating and reproducing? What specific cues might these individuals be picking up during this sensitive period?

\section{CONSEQUENCES OF FAMILY S'TRUCTURE}

Our hypothesis to account for findings in the literature about father absence is the following:

1) A male who perceives early in his childhood, during a sensitive period, that the appropriate male strategy is stable pair bonding and male provision of resources to a nuclear family will, during his later development, be more interested in objects and technology and less interested in interpersonal aggression, dominance striving, and interpersonal manipulative skills.

2) A male who perceives early that the appropriate male strategy is not stable parentalism will be more interested in and learn more easily interpersonal competitive and manipulative skills and face-to-face dominance striving, but not always physical aggressive violence.

We postulate that the consequences of father absence as described by educators, psychologists, anthropologists, and sociologists are due to this early channeling of preference. The higher scores on verbal tasks and tests given to father-absent males reflect increased interest and facility in interpersonal manipulation, verbal competitiveness, and sometimes (depending on the social context of later development) physical competitiveness, violence, and the complex of "protest masculinty."

The few studies of father-absent females are consonant with the evolutionary perspective that:

1) Females who perceive early that male parental effort is important to their reproduction will be more careful and reticent at adolescence in forming sexual relationships and will form more stable pair bonds.

2) Father-absent females will perceive that male parental effort is not crucial to reproduction and will be less coy and reticent, will engage in sexual activity earlier and with less discrimination, and will form less stable pair bonds.

Below we will outline some of the theory and empirical findings from contemporary behavioral biology which we believe to be directly relevant to the study of father absence, and we will review in greater detail findings from the various social sciences concerning this phenomenon. At this point we need to clarify a central term we are using here and throughout the paper. "Perceive" implies that the individual detects 
or registers something in the environment which has the effect of switching a developmental track; such "perception" carries with it no connotation of conscious recognition. Psychologists use similarly defined concepts of early learning and perception in their thinking about father absence, but we wish to point out that what, precisely, the child perceives is not at all well understood. Typically the assumption is that the presence or absence of the father in the home environment is the crucial environmental cue which children detect. Possibly this is a mistaken notion. For example, the effects of father absence appear to be reversed in the children of widows as contrasted with the children of divorcees (Hetherington 1972). This suggests that children perceive the relevant cues from their mothers, but as yet there is little information in the literature hinting at the actual nature of mechanisms which catalyze a developmental track of this sort. If humans are designed to perceive family organization they would do well to pay attention to the mother, a more reliable informant because of her certainty of maternity and her more durable ties to offspring. In any event, from our point of view the primary significance of the sensitive period is that individuals can begin a long period of selective observation and practice in the kinds of skills which they perceive will lead to reproductive success.

\section{SEX DIFFERENCES IN COGNITION}

There is a large literature on sex differences in cognition. The way these differences are described and categorized represent conventional, culture-bound categories, which often arise from the labeling given patterns of response (factors) to written tests. For example, females ordinarily excel in "verbal ability," while males have greater "spatial" and "quantitative" ability. Many of these sex differences are consequences of evolved sex differences in brain organization and function (Goy and McEwen 1981), and an appropriate labeling, derived from evolutionary considerations rather than from intuition, is that females are more interested than males in people, in sociality, and in interpersonal relationships, including competition in many species (see Garai and Scheinfeld 1968; Hoffman 1977; Oetzel 1966; and Draper $1975 \mathrm{~b}$ for a discussion of sex differences in sociability and affiliation; Hrdy 1981 for a discussion of competitive propensities in female primates).

The proximate cause ot these sex differences in preference and ability is probably the sensitization of the fetal male brain by testosterone during intrauterine life (Money and Ehrhardt 1972; McEwen 1976; Goy and McEwen 1980), while the final cause is the asymmetry in reproductive and other social adaptations of the sexes discussed above. Hence, prenatal brain differentiation is, in our view, functionally much the same as postnatal brain differentiation, although the mechanisms may be quite different.

These very general, underlying sex differences can be modified by socialization, and we propose that early perception of family structure and patterns of parental investment changes the patterning of these preferences. This phenotypic flexibility reflects the great diversity of mating strategies in human cultures and the consequent diversity of mating ecologies through which any set of human genetic material has passed over the last several thousands of years. 


\section{MATING AND PARENTING IN MAMMALS}

The anatomy and physiology of reproduction in mammals leaves scope for asymmetries between the sexes in the amount of time, energy, and risk devoted to reproduction. Current theory borrows heavily from Trivers's (1972) definition and discussion of parental investment and from Maynard-Smith's (1976) use of the formalism of game theory to describe the evolution of strategies and strategy mixes. An excellent summary is found in Dawkins (1976:Chapter 9). Trivers's theory relates sex differences in parental investment to other aspects of reproduction and relations between the sexes in animals. The ideas proceed from considering how an organism should budget its time, energy, and other resources among competing demands of growth, maintenance and repair, reproduction, and so forth, in such a way that fitness is maximized. Reproduction consists of two phases-courtship and mating prior to fertilization, and parental care, broadly defined, after fertilization. Parental investment is the allocation of time, energy, risk, and resources to the care and nurturance of offspring, reducing the amounts available to alternative activities.

Mammalian physiology requires at minimum almost no parental investment from males, while females must commit a lot. This asymmetry of obligate parental investment leads to sex differences in patterns, or "strategies," of reproductive behavior. Unlike the male, whose reproductive success may be furthered by impregnating as many females as possible, the female's reproductive success is limited by the time, energy, and risk costs of ovulation, conception, successful parturition and, in the case of altricial (relatively helpless) young, the constraints of nurturing her offsrping until they can survive on their own. Females of most mammalian species, given a lower ceiling on ultimate reproductive potential, should show greater discrimination regarding mate choice and timing of reproduction than is shown by males and greater commitment to parental effort. Similarly, the sexes differ in their modes of interacting with the opposite sex. The male in some ways takes the initiative in sexual contact, for example in establishing a base from which to attract females by courtship displays and in discouraging other males. The female approach, on the other hand, seems in many species to consist of choice and discrimination, whenever this is possible or useful. Where this choice is impossible or pointless, she may engage instead in passive but powerful signaling, for example with the pheromones released during estrus.

\section{Mammalian Males}

Males can vary their commitment of resources between the extremes of maximizing copulation with a large number of females, the "cad strategy," and maximizing provision of parental care to their offspring, the "dad strategy." Among mammals the empirical correlates of the cad strategy are male dominance hierarchies, male-male aggression and often violence, and high morphological dimorphism between the sexes, since in this situation the fitness of a male seems to be determined primarily by competition with other males. Well-known examples of species with cad mating organization are elephant seals (LeBouef 1974), anubis baboons on the savannah (DeVore 1965), and most herd ungulates. It is sometimes claimed that female choice is important to male reproductive success in these groups, but there is controversy about whether it actually occurs when the male contributes neither resources nor protection to the female (see Williams 1975). 
In contrast, when male parental effort is high, the empirical correlates for numerous species are relatively stable, male-female monogamous associations, reduced male-male competition for access to females, and reduced dimorphism. Familiar examples include gibbons, beavers, and wolves in some areas.

\section{Mammalian Females}

There is a corresponding strategy spectrum for females. In the face of males who will not provide parental effort, females may maximize reproductive success by minimizing time loss. They then reproduce early, with little or no concern for their mate or mates. Hrdy (1981) suggests that in many social species selection has favored outright promiscuity in females, thus defusing tendencies in males to harm or kill infants in the future. At any rate, with her large reproductive commitment and her limited reproductive potential, female investment in each offspring ought to be great relative to that of the male, and this is in fact what is observed. On the other hand, in groups where there are males willing to invest heavily in offsrping, females may delay sexual bonding and refuse any male save one who will be a reliable partner and provisioner for her and the offspring of the mating. This strategy will favor the ability of females to predict the behavior of males and it will favor sexual reticence and coyness in females. These abilities allow her to avoid pregnancy without a stable mate and assure the mate that he is in fact the father of offspring born.

In groups where such a cautious reproductive style is practiced, there is considerable courtship prior to mating. The female tests the qualities of the male as potential mate, and the male assures himself during the same period that the female is not already pregnant by some other male.

\section{Human Males}

What relationship does the spectrum of mammalian reproductive strategies have to do with human male reproductive roles? Insofar as cultural rules are concerned, the range of male parental investment is much narrower than the range among mammals. Individual males, on the other hand, can and do show parenting ranging from nothing after insemination to direct nurturance lasting well into adulthood. When we look at societies with customs favoring low or high male parentalism, there are sets of linked practices reminiscent of the reproductive practices of various other species of mammals along a spectrum from low to high male parental investment. We will use parentalism in this paper to imply, in humans, the direct or indirect provision of resources to a male's own offspring and his spouse. We do not mean by parentalism any proximal indicators, such as father-infant closeness as studied by West and Konner (1976). We expect no correlation between such indicators and parental investment as we define it; "kissing babies" costs males almost nothing in energy, time, or risk. Females and children should use other indicators to assess male parentalism, and they in fact seem to.

There is no narrow genetic determination of human male strategy; human reproductive strategy is plastic and facultative, depending upon various environmental conditions including cultural sanction. At one end of the continuum, in societies with regular, low male parental investment, the following constellation of traits appears more or less regularly: (1) segregation of adult males from women and children in many daily activities, such as eating, sleeping, working, and resting; (2) high levels of aggression and competitive display among males, usually including 
much bombast and rhetoric and occasionally including outright physical violence; (3) sex-role asymmetry, in which male dominance and female subordinance are pervasively established in secular and sacred spheres of social organization; and (4) sex-role antagonism, by which we mean that men and women hold stereotypically negative and hostile attitudes toward the opposite sex (Schuster 1979; Murphy and Murphy 1974; Meggitt 1964, 1977; Kelekna 1981; LeVine and LeVine 1966; Whiting and Whiting 1975).

We think it worthwhile to point out that while marriage occurs in all known human societies (although ethnographers have had to strain to find it in a few; cf. Gough (1979), the fact of marriage does not imply necessarily what Westerners would think of as paternal obligations on the part of fathers to their young. In many groups the relationships between husbands and wives and between fathers and their young children are typically remote. The father does not play a role in the socializing of the child because of the social and spatial segregation of the sexes and because males do not concern themselves with the daily maintenance of the young.

Similarly the father's role as breadwinner may be truncated. In areas of female farming observable in much of rural, traditional Africa and other areas of lowintensity horticulture, women raise, harvest, and process much of the food which they and their offspring require (Boserup 1970). When sex roles are segregated in these ways, the role of adult males is peripheral to the daily interaction of mothers and children, but their role is not superfluous. Men contribute more indirectly to the wife and offspring. For example, men (often working in all-male groups) provide infrequent heavy labor in the form of clearing gardens, building houes, and sometimes providing meat from domestic stock or from wild species when hunting and fishing are available. ${ }^{2}$ Defense obligations may exist, as when men protect noncombatant members of the group from attack by enemy males, or when men protect wives and female kin from sexual attack or exploitation by other males (West and Konner 1976). The reasons that men do these things seem often to be part of the domain of male-male interaction, since they are not narrowly beneficient to the male's own offspring. We do not consider these functions to be male parental investment as we are using the term.

Human Females

Earlier in this paper we presented a brief overview of the findings regarding father absence and female development. These studies derive exclusively from psychologists and educators working in modern, Western populations. Anthropologists have had little to say about the consequences of father absence for females.

Findings within American society fit the evolutionary paradigm of reproductive style, in terms of attitudes of father-absent, adolescent females to males and masculinity, interest in sexuality, timing of appearance of sexual interest, ability to develop a stable relationship with one male, and teenage pregnancy rates. In general, fatherabsent adolescent girls show "precocious" sexual interest in boys, a denigrating attitude toward males and masculinity, and little interest in maintaining sexual and emotional ties to one male.

The fascinating paper by Hetherington (1972) is central to the development of our thinking on this topic, because it controls for many of the variables we regard as pivotal for the development of mating strategy. Her subjects were adolescent, 
white females, ages 13 to 17 , an age at which the behaviors of interest should be expressed. They were categorized according to their age at interruption of fatheringsome in early childhood, some in middle childhood. They were recruited from intact, father-present households, from father-absent households created by divorce or desertion, and from father-absent households created by the death of the father. Two kinds of information about the adolescent girls were collected, only one of which gave meaningful results to Hetherington or to us. First, the girls were given paper-and-pencil tests of sex-role identification and preference; these data did not show differences among the subjects of various household structures. Second, behavior of the adolescents in the context of interviews with adult male interviewers did reveal important and strong differences among the subjects.

The adolescent girls from divorced homes showed very clearly what can be described as heightened interest in the adult male interviewers. They sat closer during the interview, engaged in more eye contact, and displayed postures indicating greater relaxation and flirtatiousness. Father-present girls indicated less interest, less openness in terms of postural cues, and less eye contact. Girls from widowed households were the least receptive to male interviewers' initiations. They sat in the most distant chairs during the interview, rarely established eye contact, and their body postures were closed and nonreceptive. There were no differences among the three categories of subjects when the interviewer was female.

Hetherington (1972) also studied interactions of the subjects with males at a community center and gathered information on the subjects' past sexual experience; she found that these indicators matched the findings described above. Elsewhere in the article Hetherington describes the behaviors of the girls from the three groups at a dance held at the community center. The father-absent girls were typically asking the boys to dance, father-present girls were usually found along the sidelines, talking to other girls, and the daughters of widows were most likely to have shut themselves up in the ladies' room for the duration of the evening.

The findings for girls from intact households and from divorced households fit neatly into our theory of evolved, sensitive-period learning of reproductive strategy. The father-present girls, relatively speaking, were not sexually aggressive and not interested in accelerating or intensifying contact with males; the daughters of families separated by divorce were practicing the "fast and early" strategy described earlier. Daughters of widows were the most cautious of all. These girls are at the coyreticent end of the female reproductive continuum, perhaps due to the inadvertent role of their mothers in communicating, to their daughters, the misfortune of widowhood. The only prominent difference between the widowed and divorced mothers was their view of their husbands and of males in general, widows idealizing and divorcees derogating their departed spouses.

Just as in males, this suggests a self-maintaining process: a female who is reared without a high-investment male shows in later years a reproductive style with fewer of those behaviors which are associated with forming durable, persistent pair bonds. She seeks sexual contact relatively early in her life. She is not excessively particular about who she mates with; her general attitude is that males are not reliable, nor particularly desirable on a long-term basis. She produces children early in her reproductive career and seeks to sustain her offspring relatively autonomously, perhaps 
with help from her own consanguines or from a male or several males who are temporary consorts. Father-absent females are then mothers to children who will themselves favor a "mating effort" reproductive style.

\section{THE WHITINGS' THEORY}

The best anthropological synthesis of the psychological implications for child development of household structure and domestic relations between men and women is found in a series of articles contributed over a period of twenty years by the Whitings and their collaborators (J. Whiting, Kluckhohn, and Anthony 1958; Burton and J. Whiting 1961; J. Whiting 1960; B. Whiting 1965; Bacon, Child, and Barry 1963; Whiting and Whiting 1975). These authors argue that when children are reared in early childhood in a predominantly feminine environment, they do not perceive the father as a controller of resources valuable to them. Therefore children do not "envy" and do not seek to emulate the father's status. Instead, they see the mother and other adult women as the all-powerful figures. This circumstance leads to the formation of an initial feminine identification on the part of a boy, later replaced by a secondary masculine identification. He is described as having a "primary cross-sex identification." According to this formulation, the boy later achieves a correct masculine identification, but only at the psychological expense of repressing the prior feminine identity. The insecure masculine secondary identification is thought to be revealed in the overly masculine "acting out" which can be seen in such individuals, most explicitly at adolescence and later ages.

The psychological theory emphasizes three notions which are also relevant to our theory: (1) the importance of the early childhood years for the psychological effects of father presence or absence to be felt; (2) the active and continuous physical involvement by the father with the child in a nurturing role; and (3) the child's perception that the father is an essential nurturing agent. Our alternative theory also emphasizes the importance of early learning. We are not as convinced that the actual presence of the father, or the child's judgment about the quality of his behavior (points 2 and 3 above), are equally critical for the child's later behavior. There are several studies which suggest that the mother's attitude toward the father and/or adult males in general can be equally influential (Parker 1975; Hetherington 1972; Friedman 1969).

\section{SYNTHESIS}

It remains to state how findings about father absence are consistent with our evolutionary interpretation. The behavioral findings of heightened male aggressiveness and the cognitive findings of heightened male verbal ability have been among the most stable in the father-absence literature. In combination, however, they are somewhat anomalous. Carlsmith (1964), for example, made no suggestion that her father-absent college freshmen evinced elements of protest masculinity. Herzog and Sudia (1973) also comment on the lack of any obvious significance which high verbal ability might have for insecure masculinity. We believe that an argument can be made for why father-absent upbringing would have these two disparate effects. 
We summarized earlier the aspects of social organization which are typically found together in normative father-absent societies. In such social systems, male rank is an important determinant of sexual access to females. A man's route to reproduction, therefore, will be mediated to a large extent by the male hierarchy. Male reproductive success may be determined very much by male-male interactions in contranormative father absent groups as well. The comparison of course is that males in father-present societies find their route to reproductive success in investing in a mate and her offspring.

A tentative hypothesis to account for the decrement in spatial skills and increase in verbal skills of father-absent males is as follows. We believe that what modern educational testing calls verbal and spatial ability, field dependence and independence, and the like, reflect an evolved dichotomy between interest in people and interest in things. Verbal ability reflects the ability to predict and manipulate the behavior of conspecifics, while spatial ability reflects attentiveness to the impersonal environment.

A male "designed" during development to reproduce in the face of male-male competition would then, by our hypothesis, specialize in interpersonal abilities leading to higher verbal competence; this aptitude is prominent in male-male competition. Miller (1959), for example, says that verbal facility ("the smarts") is the main route to status in street-gang hierarchies, and other examples of verbal specialization in contranormative, lower-class, father-absent cultures come readily to mind, such as Cockney rhyming slang. Across cultures, the bombast of Yanomamö warriors or New Guinea chiefs are familiar to any anthropology student (Chagnon 1977; Meggitt 1964).

On the other hand, a male who will follow the "dad strategy," channeling reproductive effort into provisioning a mate and offspring, should direct his attention and practice preferentially toward manipulating the impersonal environment. This would result, according to standardized tests of cognitive skills, in greater spatial and lower verbal scores.

The aggressive propensities of father-absent males would facilitate their performance in male hierarchies and competitive encounters in a social environment where sexual access to females is determined by male-male interactions. Males investing in offspring might, on the other hand, simply seek to avoid male-male aggressive encounters.

There is no reported shift in father-absent females toward increased verbal competence. The fitness of females has always depended on interpersonal abilities, so we do not expect sensitive-period switching in this domain. The fitness of females has also depended upon the correct mating strategy. The plight of upper-class Lusakan women described by Schuster (1979), who search in vain for good providers as husbands, is an excellent illustration of how coy, careful females would fare in a society of "cad" males. Fortunately for the fitness of these women, they do in fact reproduce fast and early, with little evident mate choice, belying their spoken intentions.

The sexes do not think much of each other in father-absent cultures or social groups. Males regard females as vaguely mysterious and dangerous. In the New Guinea highlands (Meggitt 1964) there are elaborate rituals to protect men from female 
dangers. In Lusaka, rape victims were denounced in the press for tempting their helpless male prey (Schuster 1979). There are two immediately obvious explanations for this pervasive fear of women. First, in terms of fitness it is entirely rational, since females are always trying to obtain resources from males, contrary to the male's (fitness) interest. Second, a male who can succeed in convincing other males that females are dangerous and best avoided would have inordinately high reproductive success. The widespread "fear of women" in such groups may be the mutually reinforced effect of individual males trying to persuade their fellows to keep away from women. Women in such groups say that males are good for nothing and not to be trusted; they are usually right, and their attitude seems to be purely rational.

\section{A NOTE ON MORAL JUDGMENTS ABOUT FAMILY STRUCTURE}

Social science literature about sex roles has failed to appreciate the lack of correspondence between evolved sex roles, or "strategies" (as we use the term), and socially appropriate sex roles, both within our own country and among other documented cultures of the world. Evolutionary success of a strategy consists simply of leaving offspring who reach reproductive maturity, while social success is an inevitably vague notion whose definition must always be culture bound, to a very large extent.

We elaborated above our perspective that males and females achieve reproductive success by following some mixture of two polar strategies. On the one hand, they can form durable pair bonds, within which sexuality is relatively exclusive and offspring are nurtured by the continuing investment of both parents. On the other hand, males and females can form a series of transient, unstable sexual relationships. In the latter case, empirically, most of an individual's social and economic ties are with same-sex groups; males typically act out their social sex role in all-male groups characterized by hierarchy, competition, and dominance striving. Females act out their social sex roles as nurturers of offspring and as members of a more or less cooperative female group, usually consisting of consanguines. Relations between sexual partners are more likely to be "aloof" in the latter case and "intimate" in the former (Whiting and Whitng 1975).

The current bias in Western thought is that the former set of strategies is correct, normal, desirable, and psychologically superior for adults of both sexes and for children; but there is no a priori reason why this should be so. Individuals pursuing either strategy can beget offspring and can see those children reach maturity. Depending on the social and economic circumstances into which children are born, one or the other strategy may prove advantageous to either parent. Western researchers who argue for the importance of the father to the child's social sex-role development consistently make two errors: (1) They do not consider whether or not children go on to achieve biological success, but instead rely upon idosyncratic measures of "adjustment" derived from their own moral and political preconceptions. (2) They do not consider that the effects of father absence may represent reproductive adaptations and that father-absent children may find it easier to pursue the second, nonbonded kind of reproductive strategy. In this context appropriate female behaviors are to engage in sex at the earliest possible age, without great regard for who 
their partners are; appropriate male behaviors are those leading to success in male interpersonal-dominance hierarchies.

\section{CONCLUSION}

The human species has multiplied rapidly, especially since the end of the Pleistocene. Much of this success has been due to our plasticity, intelligence, and adaptation via symbolically mediated cultural systems. The wide geographical spread of our species has led to occupation of a wide range of physical environments, while our intelligence and facultative plasticity have themselves generated an equally wide diversity of social environments which can change very rapidly in time and in space. Consequently, any set of human genetic material has been exposed to a diversity of social environments over the most recent tens of thousands of years, and certainly the fitness of individuals in many human societies is more dependent upon social skills than upon skills in manipulating the extrasocial environment. This unstable diversity of social environments is precisely the context where phenotypic plasticity would enjoy the greatest advantage over any fixed strategy (Cavalli-Sforza 1974).

The importance of learning in human adaptation is mirrored in our prolonged infancy and childhood and in the long interval between birth and reproductive maturity. Skills and abilities develop through practice and facilitate later performance as an adult. But the course of development is different for different individuals; determinants include both the genotype and the social and physical environment, of course. We wish to call attention especially to the role of early, or sensitiveperiod, learning in development. If prolonged practice and attention is required for the successful function of some activity in adulthood, and if at the same time there is environmental variability changing through time, but changing slowly compared to the scale of an individual lifetime, then the optimum mode of adaptation may be to establish a learning track early in development, which guides later learning and practice. Humans are unusual in the extent to which their behavior remains open, i.e., capable of being channeled through learning. It seems that human mating behavior, while clearly constrained fairly sharply by factors not susceptible to modification by learning, is "open" within a range, so that an individual can "choose" a reproductive style which is appropriate in the metric of fitness to aspects of the social environment perceived in early life.

An obvious example of the phenomenon is language learning, which occurs very easily at an early sensitive period. The particular language to be learned must be expressed in order for a child to learn it, but the child is predisposed to learn language. We suggest that the reproductive propensities discussed above and the skills and abilities which facilitate them require long learning and practice, yet the optimum strategy to be developed varies over time and even in different subgroups within the same culture.

It remains to stipulate what conditions would favor one reproductive style or strategy over another. In evolutionary theory models which specify how natural selection determines the direction and rate of change in reproductive strategy are not well developed (Maynard-Smith 1977; Orians 1969; Crook 1970). The relative success of a strategy depends in part on the physical environment, but also on the 
reproductive strategies of other individuals of both sexes, which is an aspect of the social environment. High-parental-effort males might reproduce at greater rates when energy is scarce and subsistence consists of labor-intensive exploitation of scattered resources, for example. This would be an example of how reproductive style is determined by the physical environment. These sorts of males might also be favored by the relative scarcity of other high-parental-effort males and the relative excess of discriminating females, who favor prolonged courtship. This would be an example of determination of reproductive style by aspects of the social environment. Models of the coevolution of social traits have been studied extensively by Maynard-Smith (1976) using the formalism of game theory, an approach seemingly identical with the classical approach of population genetics, which uses frequency-dependent fitnesses. In general, the relative importance of the physical and social environments in determining the course of social evolution is not well understood in biology or in anthropology, where the debate has raged under the rubric of environmental determinism.

It appears that stable pair bonds and high levels of male parental investment in ethnographically described human societies are associated with extremely laborintensive subsistence practices in some cases, for example in areas of wet-rice cultivation, as well as with centralized political systems and specialized military agencies which relieve most adult males of combatant roles (Whiting and Whiting 1975). An alternate explanation for high male parental effort in complex societies may simply be that they are densely settled, so that there is a greater payoff to male labor in agriculture than in less dense societies. Low-energy foraging societies are also widely characterized by the presence of stable nuclear families; the !Kung Bushmen are a familiar example (Draper 1975a). These cases should also be attributed to the high return, in the currency of offspring survivorship, of male subsistence labor. Harpending and Wandsnider (in press) discuss the fallacy that the !Kung obtain ample calories with little work; and Hawkes and O'Connell (1981) discuss high work loads in other hunter-gatherer groups.

How should we account for diversity of reproductive strategy among social groups within a complex society, or even among members of the same family? It is a general property of evolutionary models that when organisms suffer competition from those most similiar to themselves, a stable mix of types can persist. Whether reproductive strategy is transmitted genetically or culturally, or both, this principle should apply; there is no "best" strategy. For example, in areas of South Asia where polyandry is practiced, it is found among the wealthier, upper-socioeconomic classes. Polyandry may represent an extreme of male parental investment in human societies, and it is likely that the high male parental investment in polyandrous families has made them wealthy. It may be that the diversity in reproductive style here, however transmitted, is at the core of the maintenance of class differentiation.

A likely proximate mechanism is polymorphism in how individuals percieve the adequacy of resources. To treat the environment as if resources were plentiful is to follow the general strategy which we have associated with father absence in this paper. On the other hand, pair bonds and male labor are appropriate when resources are scarce; the polyandrous South Asians are acting as if land and male labor are in very short supply, regardless of the objective availability of calories to 
their offspring. In our own society, unmarried teenage mothers are extremely successful in the metric of fitness these days, in sharp contrast to the relatively infertile cohort of college-educated women now in the labor force, who are acting as if resources are inadequate to support successful reproduction (Yogev and Vierra, in press). Over a time scale of many generations, of course, females who reproduced fast and early may ordinarily have lost most of their offspring. Models of social strategy very often predict the maintenance of stable polymorphism, so that we should not expect any one best strategy over long time periods, at least in many ecosystems. In an interesting discussion of social class and reproduction, Dickemann (1979:324) bases her analysis on the assumption that "the relative (reproductive) success of those in high status is . . greater than that of those below." She takes status differences to be universal and assumes that appropriate strategy choices correspond to those for animals in either good or bad physical shape. While her picture of upper-class neglect and infanticide of female offspring is very well supported, it is difficult to see how this complex of treatment of females in fact benefits anyone's individual fitness. We are suggesting, on the other hand, that strategy differences themselves can and do generate class and status differences. The issue needs sharper models and better data on wealth, class, and fitness before it can be resolved.

It is not clear whether this mode of treating the environment is transmitted genetically or culturally (Mednick and Christiansen 1977), in spite of the overwhelming consensus in the social sciences that such traits are culturally transmitted. It seems to us, however, that the mechanism of sensitive-period learning described in this paper does support the hypothesis that much of the variability among human groups in this domain is culturally transmitted.

\section{NOTES}

1. This work was supported in part by NIH Grant GMO 7661. We received substantial research support from Yolanda Sarason. The following colleagues have been very helpful with comments and suggestions: Nicholas Blurton-Jones, Judith Brown, Elizabeth Cashdan, James Chisholm, Martin Etter, Jay Feierman, Sarah Hrdy, Pita Kelekna, Melvin Konner, Jeffrey Kurland, Jane Lancaster, John Pfeiffer,
Frances Purifoy, Alan Rogers, Jeremy Sabloff, Lisa Sattenspiel, Carol Smith, Eric Alden Smith, Elsa Taylor, Fritz Taylor, and Ryk Ward.

2. Sometimes game is also used by men to purchase copulation from women to whom they are not married; cf. Siskind (1973), Woodburn (1968).

\section{REFERENCES CITED}

Anderson, R.E., 1968, Where's Dad? Paternal Deprivation and Delinquency. Archives of General Psychiatry 18:641-49.

Bacon, M.K., I.L. Child, and H. Barry, 1963, A Cross-Cultural Study of Correlates of Crime. Journal of Abnormal and Social Psychology 66:291-300.

Barglow, P., M. Bornstein, D. Exum, M. Wright, and H. Visotsky, 1968, Some Psychiatric Aspects of Illegitimate Pregnancy in Early Adolescence. American Journal of Orthopsychiatry $38: 672-87$.
Biller, H.B., 1970, Father Absence and the Personality Development of the Male Child. Developmental Psychology 2:181-201.

Biller, H.B., 1971, Father, Child, and Sex Role. Lexington, Mass: D.C. Heath.

Biller, H.B., 1976, The Father and Personality Development: Paternal Deprivation and Sex Role Development. Pp. 89-156 in The Role of the Father in Child Development (ed. by M. Lamb). New York: John Wiley.

Biller, H.B., and R. Bahm, 1971, FatherAbsence, Perceived Maternal Behavior, and 
Masculinity of Self-Concept among Junior High School Boys. Developmental Psychology 4:17881.

Blanchard, R., and H.B. Biller, 1971, Father Availability and Academic Performance among Third-Grade Boys. Developmental Psychology 4:301-5.

Bloss, P., 1969, Three Typical Constellations in Female Delinquency. Pp. 99-110 in Family Dynamics and Female Sexual Delinquency (ed. by O. Pollak and A. Friedman). Palo Alto: Science and Behavior Books.

Boserup, E., 1970, Women's Role in Economic Development. London: Allen and Unwin.

Burton, R.V., and J.W.M. Whiting, 1961, The Absent Father and Cross-Sex Identity. Merrill-Palmer Quarterly of Behavior and Development $7: 85-95$.

Carlsmith, L., 1964, Effect of Early Father Absence on Scholastic Aptitude. Harvard Educational Review 34:3-21.

Cavalli-Sforza, L.L., 1974, The Role of Plasticity in Biological and Cultural Evolution. Annals of the New York Academy of Sciences 231:43-59.

Chagnon, N., 1977, Yanomamö: The Fierce People. 2nd ed. New York: Holt, Rhinehart and Winston.

Cohen, A.K., 1955, Delinquent Boys: The Culture of the Gang. Glencoe: Free Press.

Crook, J.L., 1970, The Socioecology of Primates. Pp. 103-68 in Social Behavior in Birds and Mammals (ed. by J.L. Crook). New York: Academic Press.

Dawkins, R., 1976, The Selfish Gene. London: Oxford University Press.

Dickemann, M., 1979, Female Infanticide, Reproductive Strategies, and Social Stratification: A Preliminary Model. Pp. 321-67 in Evolutionary Biology and Human Social Behavior: An Anthropological Perspective (ed. by N. Chagnon and W. Irons). North Scituate, Mass.: Duxbury.

Draper, P., 1975a, Cultural Contrasts in Sex Role Egalitarianism in Foraging and Sedentary Contexts. Pp. 77-109 in Toward an Anthropology of Women (ed. by R. Reiter). New York: Monthly Review Press.

Draper, P., 1975b, Cultural Pressure on Sex Differences. American Ethnologist 2:606-16.

Friedman, S.T., 1969, Relation of Parental Attitudes Toward Child Rearing and Patterns of Social Behavior in Middle Childhood. Psycho- logical Reports 24:575-79.

Garai, J.E., and A. Scheinfeld, 1968, Sex Differences in Mental and Behavioral Traits. Genetic Psychology Monographs 77:169-299.

Glaser, D., 1965, Social Disorganization and Delinquent Subcultures. In Juvenile Delinquency (ed. by H.C. Quay). New York: Van Nostrand.

Gough, E.K., 1959, The Nayars and the Definition of Marriage. Journal of the Royal Anthropological Institute of Great Britain and Ireland 89:23-34.

Goy, R.W., and B. McEwen, eds., 1980, Sexual Differentiation of the Brain. Cambridge, Mass.: MIT Press.

Hamilton, M., 1977, Father's Influence on Children. Chicago: Nelson-Hall.

Harpending, H., and L. Wandsnider, in press, Population Structure of Sedentary and Mobile !Kung. In Current Developments in Anthropological Genetics (ed. by M. Crawford and J. Mielke). New York: Plenum.

Hawkes, K., and J. O'Connell, 1981, Affluent Hunters? Some Comments in Light of the Alyawara Case. American Anthropologist $83: 622-26$.

Herzog, E., and C.E. Sudia, 1973, Children in Fatherless Families. Pp. 141-232 in Review of Child Development Research, vol. 3 (ed. by B.M. Caldwell and H.N. Ricciuti). Chicago: University of Chicago Press.

Hetherington, E.M., 1972, Effects of Father Absence on Personality Development in Adolescent Daughters. Developmental Psychology $7: 313-26$.

Hrdy, S.B., 1981, The Woman that Never Evolved. Cambridge, Mass.: Harvard University Press.

Kelekna, P., 1981, Sex Asymmetry in Jivaroan Achuara Society: A Cultural Mechanism Promoting Belligerence. Ph.D. diss., Albuquerque: University of New Mexico.

Kelly, F.J., and D.J. Baer, 1969, Age of Male Delinquents when Father Left Home and Recidivism. Psychological Reports 25:1010.

Le Boeuf, B.J., 1974, Male-Male Competition and Reproductive Success in Elephant Seals. American Zoologist 14:163-76.

Leonard, M.R., 1966, Fathers and Daughters. International Journal of Psychoanalysis 47: 325-33.

LeVine, R., and B. LeVine, 1966, Nyansongo: A Gusii Community. New York: Wiley.

Lynn, D.B., 1974, The Father: His Role in 
Child Development. Monterey, Cal.: Brooks and Cole.

Lynn, D.B., and W.L. Sawrey, 1959, The Effects of Father Absence on Norwegian Boys and Girls. Journal of Abnormal and Social Psychology 59:258-62.

Maynard-Smith, J., 1976, Evolution and the Theory of Games. American Scientist $64: 41-45$.

Maynard-Smith, J., 1977, Parental Investment: A Prospective Analysis. Animal Behavior 25:1-19.

McEwen, B.S., 1976, Interactions between Hormones and Nerve Tissue. Scientific American $235: 48-58$.

Mednick, S., and K.O. Christiansen, eds., 1977, Biosocial Bases of Criminal Behavior. New York: Gardner.

Meggitt, M.J., 1964, Male Female Relationships in the Highlands of New Guinea. American Anthropologist 66:204-24.

Meggitt, M.J., 1977, Blood is Their Argument. Stanford, Cal.: Mayfield.

Miller, W.B., 1958, Lower Class Culture as a Generating Milieu of Gang Delinquency. Journal of Social Issues 14:5-19.

Money, J., and A. Ehrhardt, 1972, Man and Woman, Boy and Girl. Baltimore: Johns Hopkins University Press.

Moynihan, D.P., 1965, The Negro Family: The Case for National Action. Washington: United States Dept. of Labor.

Munroe, R.L., R.H. Munroe, and J.W.M. Whiting, 1980, Male Sex-Role Resolutions. Pp. 611-32 in Handbook of Cross Cultural Human Development (ed. by R.H. Munroe, R.L. Munroe, and B. Whiting). New York: Garland STPM press.

Murphy, Y., and R. Murphy, 1974, Women of the Forest. New York: Columbia University Press.

Nash, J., 1965, The Father in Contemporary Culture and Current Psychological Literature. Child Development 36:261-97.

Nash, J., 1976, Historical and Social Changes in the Perception of the Role of the Father. Pp. 62-88 in The Role of the Father in Child Development (ed. by M.E. Lamb). New York: Wiley.

Nelsen, E.A., and P.M. Vangen, 1971, The Impact of Father Absence upon Heterosexual Behaviors and Social Development of Preadolescent Girls in a Ghetto Environment. Proceedings, 79th Annual Convention of the American
Psychological Association 6:165-66.

Nye, F.I., 1957, Child Adjustment in Broken and in Unhappy Unbroken Homes. Marriage and Family Living 19:356-61.

Orians, G.H., 1969, On the Evolution of Mating Systems in Birds and Mammals. American Naturalist 103:589-603.

Parker, S., 1975, Father Absence and Cross Sex Identity: The Puberty Rites Controversy Revisited. American Ethnologist 2:687-706.

Pettigrew, T.F., 1964, A Profile of the Negro American. Princeton: Van Nostrand.

Rainwater, L., 1971, Marital Sexuality in Four "Cultures of Poverty." Pp. 187-205 in Human Sexual Behavior: Variation in the Ethnographic Spectrum (ed. by D.S. Marshall and R.C. Suggs). New York: Basic Books.

Rohrer, J., and M. Edmonson, 1960, The Eighth Generation. New York: Harper.

Schuster, I.M.G., 1979, New Women of Lusaka. Palo Alto: Mayfield.

Siskind, J., 1973, To Hunt in the Morning. London: Oxford University Press.

Sluckin, W., 1970, Early Learning in Man and Animal. Cambridge, Eng.: Schenkman.

Trivers, R.L., 1972, Parental Investment and Sexual Selection. Pp. 136-79 in Sexual Selection and the Descent of Man, 1871-1971 (ed. by B. Campbell). Chicago: Aldine.

West, M.M., and M. Konner, 1976, The Role of the Father in Anthropological Perspective. Pp. 185-217 in The Role of the Father in Child Development (ed. by M. Lamb). New York: Wiley.

Whiting, B.B., 1965, Sex Identity Conflict and Physical Violence: A Comparative Study. American Anthropologist 67:123-40.

Whiting, J.W.M., 1960, Resource Mediation and Learning by Identification. In Personality Development in Children (ed. by I. Isco and M. Stevenson). Austin: University of Texas Press.

Whiting, J.W.M., and B.B. Whiting, 1975, Aloofness and Intimacy of Husbands and Wives: A Cross Cultural Study. Ethos 3:183207.

Whiting, J.W.M., R. Kluckhohn, and A.S. Anthony, 1958, The Function of Male Initiation Ceremonies at Puberty. Pp. 359-70 in Readings in Social Psychology (ed. by E.E. Maccoby, T. Newcomb, and E. Hart). New York: Holt.

Williams, G.C., 1975, Sex and Evolution. Princeton: Princeton University Press.

Winch, R.F., 1949, The Relation between 
Loss of Parent and Progress in Courtship. Journal of Social Psychology 29:51-56.

Winch, R.F., 1950, Some Data Bearing on the Oedipus Hypothesis. Journal of Abnormal and Social Psychology 45:481-89.

Woodburn, J., 1968, Stability and Flexibility in Hadza Residential Groupings. Pp. 103-10 in Man the Hunter (ed.by R. Lee and I. DeVore). Chicago: Aldine.
Wylie, J.L., and R.A. Delgado, 1959, A Pattern of Mother-Son Relationship Involving the Absence of the Father. American Journal of Orthopsychiatry 29:644-49.

Yogev, S., and A. Vierra, in press, An Attitudinal Explanation for Childlessness among Professional Women. Sex Roles: A Journal of Research. 